It is estimated that by the year 2043, about the time that today's new graduates will be retiring, 25\% of the population will be formed by those 65 years and over

\section{Older oral health}

A recent review, published by the British Society of Gerodontology and reported in the $B D J$ News section ${ }^{1}$ just before Christmas, has provided an important reference point for taking forward the future of oral health for older people.

The aim of the review, fully titled 'Meeting the Challenges of Oral Health for Older People: A Strategic Review'2 was commissioned and funded by the Department of Health but drew the membership of its review group from a wide range of organisations representing both dentistry (including the BDA) and older people. The aim was to evaluate the oral health needs of older people; to examine to what extent they are met by the new NHS arrangements and to provide a vision for an implementation plan to achieve their oral health care needs.

With 32 recommendations, the document provides a comprehensive overview of oral health for this cohort of the population and should become essential reading for all involved in the planning and provision of its oral care - which is just about all of us.

The review reminds us that when formulating oral health care services for older people there is a tendency to think only in terms of the frail elderly person. Consequently, the tendency is therefore also to consider that care of older people will be the remit only of dentists with special interests or, in future in view of the GDC's recent decision, Specialists in Special Care Dentistry. However, while there is certainly a need for this, the majority of dental care for older people is provided by general dental practitioners and this is likely to remain the case for the foreseeable future.

Changes both in demographics and in oral disease in the UK in recent decades will have an impact on the provision of oral care for older people. Firstly, the number of older people is increasing in absolute terms and in relative terms, with them forming a larger proportion of the population. To put this gradual trend into a longer term perspective, it is estimated that by the year 2043, about the time that today's new graduates will be retiring, 25\% of the population will be formed by those 65 years and over.

In addition this is accompanied by a much higher percentage of older people retaining some or all of their natural teeth. Consequently, these individuals have many restored teeth which are likely to require high levels of maintenance. In turn, this will result in a gradual but steady change in the type of demand created and the treatment options that will need to be provided. Add into this mix of crystal-ball gazing statistics the greater affluence among the next generation of older people, with consequently raised expectations, and it is possible to see how different the shape of their oral care will need to be, whether undertaken within or outside the NHS.

While the need for restorative treatment is likely to increase, especially in relation to root caries as well as maintenance of existing restorations, there will also be a need for prevention since, just as with oral diseases in all ages of people they are preventable. The application of oral hygiene measures, diet control and fluorides is just as important for this group as for all others and will also need to be incorporated more comprehensively into their future care.

\section{VOLUME 200}

The $B D J$ has reached the remarkable historic landmark of starting its 200th volume. To celebrate this achievement we have commissioned a special series of covers for Volume 200. We approached a number of young artists and selected 12 whose work we felt was appropriate to the task. Each of these was then commissioned for the sum of $£ 200$ to create an image for the front cover which encompassed the joint themes of 200 and oral health/dentistry.

As you will see between now and the end of June, each image is strikingly different and in order to keep alive the spirit of encouraging young artists we will then be asking you to vote for your favourite covers. From these results we will then select a smaller number of the artists and commission them to produce further covers for the Journal in due course.

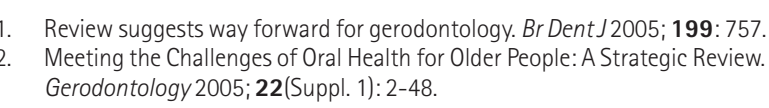

Stephen Hancocks OBE, Editor in Chief doi: $10.1038 /$ sj.bdj.4813153 